\title{
The influence of tumour necrosis factor $\alpha$ inhibitors treatment - etanercept on serum concentration of biomarkers of inflammation and cartilage turnover in psoriatic arthritis patients
}

\author{
Michał Waszczykowski ${ }^{1}$, Igor Bednarski², Aleksandra Lesiak², Elżbieta Waszczykowska ${ }^{3}$, Joanna Narbutt ${ }^{2}$, \\ Jarosław Fabiśs

\begin{abstract}
${ }^{1}$ Department of Arthroscopy, Minimally Invasive Surgery and Sports Traumatology, Medical University of Lodz, Lodz, Poland ${ }^{2}$ Dermatology, Paediatric Dermatology and Oncology Clinic, Medical University of Lodz, Lodz, Poland
\end{abstract} \\ ${ }^{3}$ Department of Dermatology and Venereology, Medical University of Lodz, Lodz, Poland
}

Adv Dermatol Allergol 2020; XXXVII (6): 995-1000 DOI: https://doi.org/10.5114/ada.2020.96705

\begin{abstract}
Introduction: Effective treatment in psoriatic arthritis (PsA) patients can protect them from severe musculoskeletal complications. For appropriate monitoring of anti-tumour necrosis factor $\alpha$ (anti-TNF- $\alpha$ ) treatment in PsA, specific biomarkers are needed.

Aim: To investigate whether biological treatment with anti-TNF- $\alpha$ (etanercept 50 mg once a week subcutaneously) affects the activity of selected mediators of inflammation and destruction of articular cartilage: interleukin- 6 (IL-6), interleukin-18 (IL-18), matrix metalloproteinases 1 and 3 (MMP-1, MMP-3), cartilage oligomeric matrix protein (COMP), human cartilage glycoprotein (YKL-40) in serum of patients with PsA.

Material and methods: The study included 25 patients with PSA. The concentration of IL-6, IL-18, MMP-1, MMP-3, COMP and YKL-40 in serum was determined before, and 6 and 12 weeks after the beginning of anti-TNF- $\alpha$ treatment. Clinical severity of the disease according to the Body Surface Area, Psoriasis Area and Severity Index and Dermatology Life Quality Index as well as tender and swollen joint count (TJC, SJC) were also evaluated.

Results: The study disclosed a statistically significant reduction in the serum concentration of IL-6, MMP-1 and YKL-40 in PsA patients after 6 and 12 weeks from the beginning of anti-TNF- $\alpha$ treatment $(p=0.00018$ for IL- 6 ; $p=0.01242$ for MMP-1; $p=0.03263$ for YKL-40).

Conclusions: IL-6, MMP-1 and YKL-40 may be useful for monitoring the effectiveness of anti-TNF- $\alpha$ treatment.
\end{abstract}

Key words: interleukin-6, interleukin-18, matrix metalloproteinases, YKL-40, COMP, psoriatic arthritis, anti-TNF- $\alpha$ treatment.

\section{Introduction}

Psoriasis arthritis (PSA) is a seronegative arthropathy accompanied by inflammatory joint changes and psoriasis [1]. Its frequency is estimated at $0.2-1 \%$ of the population [2]. The Classification Criteria for Psoriatic Arthritis (CASPAR) are key in the diagnosis of PSA [3]. Early diagnosis and effective treatment protect patients from complications and severe consequences of the musculoskeletal system. In order to understand the exact etiopathogenesis of this disease, its early detection and effective treatment, various biomarkers specific to this disease are investigated [1, 4-8]. According to the National Institutes of Health Biomarkers Definitions
Working Group, a biomarker is "a characteristic that is objectively measured and evaluated as an indicator of normal biological processes, pathogenic processes, or pharmacologic responses to therapeutic intervention" [9]. Their identification allows for earlier treatment and monitoring the therapy. Nowadays, tumour necrosis factor $\alpha$ (TNF- $\alpha)$ inhibitors have been a recognized, accepted and effective treatment for PsA patients [10]. Not only TNF- $\alpha$, but also interleukin-6 (IL-6), interleukin-18 (IL-18), metalloproteinases 1 and 3 (MMP-1, MMP-3) are key mediators of inflammatory processes in PSA, and their blocking allows to reduce the development of the disease and adverse consequences of joint changes [7, 11-13].

Address for correspondence: Michał Waszczykowski MD, PhD, Department of Arthroscopy, Minimally Invasive Surgery and Sports Traumatology, Medical University of Lodz, 4 Kosciuszki St, 90-419 Lodz, Poland, phone: +48 693865 999, e-mail: mwaszczykowski@wp.pl Received: 10.05.2020, accepted: 28.05.2020. 


\section{Aim}

Numerous studies have been undertaken in recent years to identify markers in the serum of PsA patients which may be specific to this disease and differentiate it from others $[4-6,11,13]$. Some of them are responsible for the course of inflammatory processes, others for the degradation and repair of articular cartilage [5, 6, 11, 13]. However, we still do not know much about how the biological treatment with TNF- $\alpha$ inhibitors affects their serum activity in patients with PSA and whether monitoring of their concentrations may be useful in assessing the effectiveness of the therapy.

Therefore, the aim of our study was to investigate whether biological treatment with anti-TNF- $\alpha$ (etanercept $50 \mathrm{mg}$ once a week subcutaneously) affects the activity of selected mediators of inflammation and destruction of articular cartilage (IL-6, IL-18, MMP-1, MMP-3, COMP, YKL-40) in serum of patients with PsA.

\section{Material and methods}

\section{Study group}

Patients were qualified for the study at the Orthopaedic Outpatient Clinic and the Department of Dermatology and Venereology of the Medical University of Lodz. Based on the clinical examination and the Classification of Psoriatic Arthritis Study Group (CASPAR) criteria, the diagnosis of psoriatic arthritis (PSA) was made [3]. All the PsA patients presented simultaneously with moderate plaque psoriasis. Most PsA patients (80\%) had an asymmetric type of the disease and involvement of few joints. In $45 \%$ of them, nail changes (subungual hyperkeratosis, pitting) were observed. In $20 \%$ of the patients we diagnosed a symmetrical form of PsA with nails involvement in all the cases. In all patients C-reactive protein (CRP) and erythrocytes sedimentation rate (ESR) were determined in peripheral blood serum. Patients with a history of past or present other immunological diseases (RA, Crohn's disease), neoplastic diseases and acute or past significant injuries were excluded from the study. Patients with the active PsA status, who did not react to the standard disease-modifying anti-rheumatic drugs (DMARDs) and were not treated previously with anti-TNF drugs were qualified for the study. All patients gave informed and written consent to participate in the study. The local Bioethics Committee accepted and agreed to the study (consent number: RNN/36/06/KB), which was performed in accordance with the Helsinki Declaration.

\section{Clinical evaluation}

The Body Surface Area score (BSA), Psoriasis Area and Severity Index (PASI) and Dermatology Life Quality Index (DLQI) as well as joints involvement assessment: 68 tender and 66 swollen joint count (TJC, SJC) were used in the clinical evaluation of the disease [14-18].

\section{Determination of serum concentration} of biomarkers of inflammation and cartilage turnover

Subsequently, IL-6, IL-18, IL-20, MMP-1, MMP-3, COMP and YKL-40 serum concentration measurements were performed with enzyme-linked immunosorbent assay (ELISA) kits. Peripheral blood samples were taken from each patient in the morning, then centrifuged and obtained serum was deposited into $1.5 \mathrm{ml}$ Eppendorf's tubes, which were then sealed, frozen and stored at $-80^{\circ} \mathrm{C}$ for further immunoenzymatic determinations. Then, measurements of serum concentrations of IL-6, IL18, MMP-1, MMP-3, COMP and YKL-40 were performed using ELISA - enzyme-linked immunosorbent assay sets from R\&D Systems Europe, Ltd, Abingdon, UK (IL-6, IL-18, MMP-1, MMP-3), BioVendor GmbH, Heidelberg, Germany (COMP), Metra Quidel, San Diego, USA (YKL-40) according to the manufacturers' instructions. A minimum detection level has been set as $0.7 \mathrm{pg} / \mathrm{ml}$ for IL-6, $4.57 \mathrm{pg} / \mathrm{ml}$ for IL-18, $0.095 \mathrm{ng} / \mathrm{ml}$ for MMP-1, $0.045 \mathrm{ng} / \mathrm{ml}$ for MMP-3, $0.4 \mathrm{ng} / \mathrm{ml}$ for COMP and $10 \mathrm{ng} / \mathrm{ml}$ for YKL-40.

The same activities (blood collection, centrifugation, freezing and storage, concentration measurements) were performed 6 and 12 weeks after the beginning of antiTNF- $\alpha$ treatment (etanercept 50 mg per week subcutaneously). These analyses were performed according to the previously presented protocol using the same ELISA kit.

\section{Statistical analysis}

Distribution of variables was evaluated using Shapiro-Wilk test. To compare differences between each time point, Friedman's ANOVA with post-hoc testing was employed. Correlations between each variable was examined using Spearman's rank correlation. A p-value below 0.05 was considered statistically significant. All calculations were made using Statistica 13 software.

\section{Results}

Finally, 25 patients (56\% males and $44 \%$ females) aged between 32 and 71 years (mean 53.44 years) were qualified for the analysis (Table 1 ). The results of clinical and laboratory assessment of these patients according to PASI, DLQI, BSA, CRP, ESR and TJC+SJC were shown in Table 1. The results showed a statistically significant improvement of the clinical status according to PASI and TCJ + SJC after 12 weeks of anti-TNF- $\alpha$ treatment (Table 1). In addition, the reduction in the CRP and ESR levels was also seen after the treatment (Table 1). We found a statistically significant reduction in the serum concentration of IL-6, MMP-1 and YKL-40 in PsA patients after 6 and 12 weeks from the beginning of anti-TNF- $\alpha$ treatment ( $p=0.00018$ for IL-6; $p=0.01242$ for MMP-1; $p=0.03263$ for YKL-40; Table 2, Figure 1). The reduction in the serum level of MMP-3 was also marked but not statistically significant ( $p=0.06573$, Table 2 , Figure 1 ). 
Although anti-TNF- $\alpha$ treatment resulted in an almost twofold decrease in the serum IL-18 level $(60.90 \pm 63.72$ $\mathrm{pg} / \mathrm{ml}$ before treatment vs. $36.87 \pm 26.01 \mathrm{pg} / \mathrm{ml} 12$ weeks after treatment beginning), this decrease was not statistically significant ( $p=0.51342$, Table 2 , Figure 1$)$. Interestingly, we also found that the serum COMP level increased slightly after 6 weeks of anti-TNF- $\alpha$ treatment, to return almost to baseline after 12 weeks (Table 2, Figure 1).

Our data also indicated that the serum MMP-1 level in the PsA study group positively correlated with the level of serum COMP before and 12 weeks after anti-TNF- $\alpha$ treatment (Table 2). We also found a moderate correlation between IL- 6 and MMP-3 and IL-18 serum concentrations before anti-TNF- $\alpha$ treatment (Table 3). Moreover, our analysis also showed moderate correlations between MMP-3 and YKL-40 serum levels 6 weeks after anti-TNF- $\alpha$ treatment (Table 3).

\section{Discussion}

In this study we tried to assess the influence of biological treatment of anti-TNF- $\alpha$ on the concentration of studied interleukins and markers of inflammation and destruction of articular cartilage in serum in patients with PsA. Our results showed that anti-TNF- $\alpha$ treatment has a significant effect on the IL- 6 level, decreased its concentrations in serum after 6 and 12 weeks from the beginning of treatment. There are only a few data in the literature on the effect of anti-TNF- $\alpha$ treatment on serum IL-6 levels in PsA patients. Although, both Ramonda et al. and Amital et al. indicate in their studies that the treatment with TNF- $\alpha$ blockers did not have a significant effect on the change in serum IL-6 levels in patients with PsA, we believe, based on our research and previous studies on the role of IL- 6 in the etiopathogenesis of PSA, that this cytokine may play an important role in monitoring the effectiveness of anti-TNF- $\alpha$ treatment $[12,13,19$, 20]. This, however, requires further research and study.

Furthermore, we found a statistically significant reduction in serum concentration of YKL-40 in PsA patients after 6 and 12 weeks from the beginning of anti-TNF- $\alpha$ treatment. Also Jensen et al. have shown that biological treatment of anti-TNF- $\alpha$ significantly reduces YKL-
Table 1. Clinical and laboratory parameters in the study (PsA) group before and after 12 weeks of anti-TNF- $\alpha$ treatment

\begin{tabular}{|c|c|c|c|}
\hline Parameter & $\begin{array}{c}\text { PsA }(N=25) \\
\text { (before treatment) }\end{array}$ & $\begin{array}{c}\text { PsA }(N=25) \\
\text { (after } 12 \text { weeks) }\end{array}$ & $P$-value \\
\hline $\begin{array}{l}\text { Mean age } \\
\text { [years]* }\end{array}$ & $53.44 \pm 8.32$ & $53.44 \pm 8.32$ & - \\
\hline $\begin{array}{l}\text { Males/ } \\
\text { females (\%) }\end{array}$ & $56 / 44$ & $56 / 44$ & - \\
\hline PASI (\%)* & $16.51 \pm 3.88$ & $7.15 \pm 1.98$ & $<0.0001$ \\
\hline DLQI* & $14.04 \pm 1.83$ & - & - \\
\hline BSA $(\%)^{*}$ & $25.91 \pm 8.33$ & - & - \\
\hline $\mathrm{CRP}[\mathrm{mg} / \mathrm{l}]^{\star}$ & $9.62 \pm 7.87$ & $3.34 \pm 2.18$ & 0.0002 \\
\hline $\mathrm{ESR}[\mathrm{mm} / \mathrm{h}]^{\star}$ & $12.54 \pm 7.18$ & $4.75 \pm 2.84$ & $<0.0001$ \\
\hline $\mathrm{TJC}+\mathrm{SJC}^{*}$ & $10.73 \pm 2.28$ & $4.82 \pm 1.01$ & $<0.0001$ \\
\hline
\end{tabular}

*The values are given as a mean with standard deviation.

40 serum levels in PsA patients (responders) during the 4-6 week observation period and this decrease correlates with clinical results on the PASI and CRP scales [21]. However, they did not demonstrate that the treatment had an effect on YKL-40 decrease in patients with the skin form of psoriasis [21]. It seems that the decrease in YKL-40 levels during treatment with TNF- $\alpha$ blockers may reflect the healing and repair of cartilage. This indicates that YKL-40 may be a good biomarker for monitoring the effectiveness of this treatment in PSA patients.

The results of our study show that this treatment also has an influence on the serum concentration of MMP-1. We observed a statistically significant reduction in the serum concentration of MMP-1 in the study group after anti-TNF- $\alpha$ treatment. Unfortunately, there is no information in the available databases about the effect of biological treatment on this biomarker in patients with PsA. MMP-1 plays an important role in inflammatory processes in PsA. Therefore, it seems to us that our results may indicate that MMP-1 may be a useful biomarker for monitoring the effectiveness of anti-TNF- $\alpha$ treatment. However, further studies should be continued in this field.

We also noticed a decrease in the IL-18 level both after 6 and 12 weeks of treatment, but these were not

Table 2. Inflammatory cytokines and cartilage turnover markers serum concentration changes in the study (PsA) group during anti-TNF- $\alpha$ treatment

\begin{tabular}{lcccc}
\hline Parameter & Before treatment & After 6 weeks & After 12 weeks & $P$-value \\
\hline MMP-1 [ng/ml] & $4.19 \pm 2.10$ & $3.44 \pm 1.72$ & $3.04 \pm 1.58$ & 0.01242 \\
\hline MMP-3 [ng/ml] & $22.14 \pm 17.68$ & $22.44 \pm 16.70$ & $18.29 \pm 12.83$ & 0.06573 \\
\hline $\mathrm{IL}-6[\mathrm{pg} / \mathrm{ml}]$ & $4.15 \pm 4.42$ & $1.65 \pm 2.72$ & $1.06 \pm 0.89$ & 0.00018 \\
\hline $\mathrm{IL}-18[\mathrm{pg} / \mathrm{ml}]$ & $60.90 \pm 63.72$ & $29.55 \pm 20.49$ & $36.87 \pm 26.01$ & 0.51342 \\
\hline YKL-40 [ng/ml] & $70.48 \pm 34.02$ & $63.97 \pm 57.65$ & $57.16 \pm 33.55$ & 0.03263 \\
\hline COMP $[\mathrm{ng} / \mathrm{ml}]$ & $2635.03 \pm 446.00$ & $2720.04 \pm 602.55$ & $2589.34 \pm 734.55$ & 0.51342 \\
\hline
\end{tabular}

The values are given as a mean with standard deviation. 

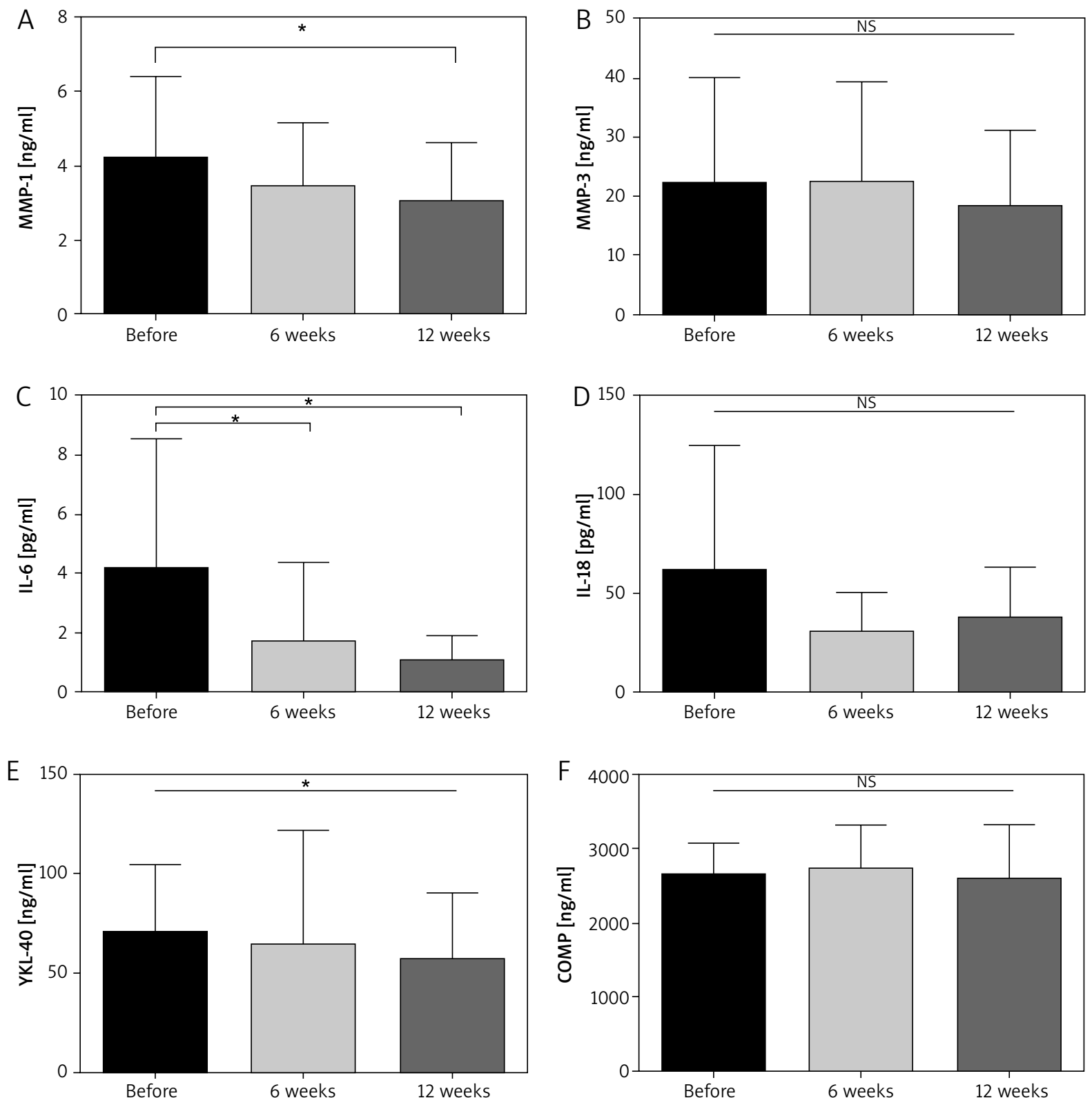

Figure 1. Inflammatory cytokines and cartilage turnover biomarkers serum concentration changes in the study (PsA) group during anti-TNF- $\alpha$ treatment. Boxes represent mean value, whiskers standard deviation. Asterisks above boxes indicate the following $p$-values: ${ }^{*} p<0.05,{ }^{* *} p<0.001,{ }^{* * *} p<0.0001$

Table 3. Significant Spearman's correlation coefficients between studied inflammatory/cartilage biomarkers in serum

\begin{tabular}{lccc}
\hline Parameter & Pair of parameters $(N=25)$ & $R$ & $P$-value \\
\hline Before & MMP-1 \& COMP & 0.44 & 0.0286 \\
\cline { 2 - 4 } treatment & IL-6 \& MMP-3 & 0.47 & 0.0182 \\
\cline { 2 - 4 } & IL-6 \& IL-18 & 0.41 & 0.0441 \\
\hline 6 weeks & MMP-3 \& YKL-40 & 0.51 & 0.0150 \\
\hline 12 weeks & MMP-1 \& COMP & 0.51 & 0.0319 \\
\hline
\end{tabular}

statistically significant. There are no data in the literature on the effect of anti-TNF- $\alpha$ treatment on serum IL-18 levels in PSA patients. Our study is probably the first to address this issue. However, attempts have been made to monitor the effect of TNF- $\alpha$ inhibitors on serum IL-18 levels in patients with RA. Pittoni et al. in their study have shown a statistically significant reduction in the serum IL-18 concentration in RA patients after infliximab treatment [22]. Bresnihan et al. also found that treatment of patients with PsA (methotrexate 12.5-20 mg/week) reduces serum IL-18 levels after 6 weeks of treatment, but this decrease was not statistically significant [23]. 
Furthermore, we also found the reduction in the serum concentration of MMP-3 in PSA patients after antiTNF- $\alpha$ treatment but it was not statistically significant. Ramonda et al. however, in their study noted a statistically significant decrease in serum levels of MMP-3 in PsA patients after anti-TNF- $\alpha$ treatment (etanercept $50 \mathrm{mg} /$ week) [19]. Van Kuijk et al. also have shown in their analysis that treatment with anti-TNF- $\alpha$ (adalimumab at a dose of $40 \mathrm{mg}$ per week subcutaneously) has a statistically significant effect on lowering serum MMP-3 levels in PsA patients [24]. Similar observations were made by Chandran et al. and Mahendran and Chandran $[25,26]$. They also found that anti-TNF- $\alpha$ treatment (etanercept, adalimumab, golimumab, infliximab) significantly reduces serum MMP-3 levels in PsA patients. This is probably related to the inhibitory effect of this treatment on synovial fibroblasts. They also believe that MMP-3 can be a good marker of biological treatment efficacy in PsA patients. We also agree with them, even though we did not achieve statistical significance in reduction of the MMP-3 level during anti-TNFa treatment. MMP-3 is the main biomarker involved in the destruction of articular cartilage in PsA. A decrease in the level of MMP-3 in serum during anti-TNF- $\alpha$ treatment may indicate a good response to this treatment. In addition, the positive correlation, we have shown, between the decrease in the serum level of MMP-3 and YKL-40 may prove that the observation of key markers of cartilage turnover is important for monitoring the effectiveness of anti-TNF- $\alpha$ treatment.

When examining the effect of biological treatment on serum COMP levels in PsA patients, we observed no significant decrease in this marker after the treatment. These observations are consistent with studies of van Kuijk, Chandran and Mahendran [24-26]. Moreover, our results indicate that due to biological treatment there may be a small increase in COMP levels in this group of patients, although this increase was not statistically significant. Chandran et al. also noted in their study that treatment may slightly increase the serum COMP levels of PsA patients during this therapy [25]. This, in turn, may be an expression of cartilage healing processes, which may also be seen in the radiological examination [25-27]. However other results were presented by Cauza et al. [28]. They found that infliximab treatment clearly lowers COMP levels 6 weeks after the beginning of anti-TNF- $\alpha$ treatment [28].

However, our work has several shortcomings. The first of them is a relatively small group of patients. We selectively qualified patients who were treated only with etanercept. It is possible to extend the study group and include also patients who were treated with other antiTNF- $\alpha$ blockers. Another limitation is the lack of randomization of the study group. It also seems advisable to analyse these biomarkers also in synovial fluid. This would allow for a wider range of results, also analysing the synovial membrane response to the treatment.

\section{Conclusions}

The results of our study show that anti-TNFa treatment with etanercept can reduce significantly the serum concentrations of IL-6, MMP-1 and YKL-40 in PSA patients. These biomarkers may therefore be useful for monitoring the effectiveness of anti-TNF- $\alpha$ treatment. Moreover, the changes in YKL-40 serum concentration may be related to the articular cartilage repair process during the treatment. However, this requires further studies and observations.

\section{Acknowledgments}

The study was supported by internal funds of the Medical University of Lodz, Lodz, Poland (grant numbers: 503/1-040-02/503-51-001-1900; 503/5-064-04/503-01 and 503/1-152-01/503-11-001-1900).

\section{Conflict of interest}

The authors declare no conflict of interest.

\section{References}

1. de Vlam K, Gottlieb AB, Mease PJ. Current concepts in psoriatic arthritis: pathogenesis and management. Acta Derm Venereol 2014; 94: 627-34.

2. Chang CA, Gottlieb AB, Lizzul PF. Management of psoriatic arthritis from the view of the dermatologist. Nat Rev Rheumatol 2011; 7: 588-98.

3. Taylor W, Gladman D, Helliwell P, et al. Classification criteria for psoriatic arthritis: development of new criteria from a large international study. Arthritis Rheum 2006; 54 : 2665-73.

4. Bartosińska J, Zakrzewska E, Purkot J, et al. Decreased blood CD4+PD-1+ and CD8+PD-1+ T cells in psoriatic patients with and without arthritis. Adv Dermatol Allergol 2018; 35: 34450.

5. Cretu D, Prassas I, Saraon P, et al. Identification of psoriatic arthritis mediators in synovial fluid by quantitative mass spectrometry. Clin Proteomics 2014; 11: 27.

6. Waszczykowski M, Bednarski I, Narbutt J, et al. Interleukin-18, interleukin-20, and matrix metalloproteinases (MMP-1, MMP-3) as markers of psoriatic arthritis disease severity and their correlations with biomarkers of inflammation and turnover of joint cartilage. Adv Dermatol Allergol 2020; doi:10.5114/ada.2020.94903.

7. Gracie JA, Forsey RJ, Chan WL, et al. A proinflammatory role for IL-18 in rheumatoid arthritis. J Clin Invest 1999; 104: 1393401.

8. Owczarczyk-Saczonek A, Drozdowski M, Maciejewska-Radomska A, et al. The effect of subcutaneous methotrexate on markers of metabolic syndrome in psoriatic patients preliminary report. Adv Dermatol Allergol 2018; 35: 53-9.

9. Biomarkers Definitions Working Group. Biomarkers and surrogate endpoints: Preferred definitions and conceptual framework. Clin Pharmacol Ther 2001; 69: 89-95.

10. Coates LC, Kavanaugh A, Mease PJ, et al. Group for Research and Assessment of Psoriasis and Psoriatic Arthritis 2015 Treatment Recommendations for Psoriatic Arthritis. Arthritis Rheumatol 2016; 68: 1060-71. 
11. Skoumal M, Haberhauer G, Fink A, et al. Increased serum levels of cartilage oligomeric matrix protein in patients with psoriasis vulgaris: a marker for unknown peripheral joint involvement? Clin Exp Rheumatol 2008; 26: 1087-90.

12. Alenius GM, Eriksson C, Rantapää Dahlqvist S. Interleukin-6 and soluble interleukin-2 receptor alpha-markers of inflammation in patients with psoriatic arthritis? Clin Exp Rheumatol 2009; 27: 120-3.

13. Chandran V, Scher JU. Biomarkers in psoriatic arthritis: recent progress. Curr Rheumatol Rep 2014; 16: 453.

14. Mease PJ. Measures of psoriatic arthritis. Arthritis Care Res (Hoboken) 2011; 63 Suppl 11: S64-85.

15. Long CC, Finlay AY. The finger-tip unit: a new practical measure. Clin Exp Dermatol 1991; 16: 444-7.

16. Ashcroft DM, Wan Po AL, Williams HC, Griffiths CE. Clinical measures of disease severity and outcome in psoriasis: a critical appraisal of their quality. Br J Dermatol 1999; 141: 185-91.

17. Finlay AY, Khan GK. Dermatology Life Quality Index (DLQI): a simple practical measure for routine clinical use. Clin Exp Dermatol 1994; 19: 210-6.

18. Gladman DD, Mease PJ, Strand V, et al. Consensus on a core set of domains for psoriatic arthritis. J Rheumatol 2007; 34: 1167-70.

19. Ramonda R, Puato M, Punzi L, et al. Atherosclerosis progression in psoriatic arthritis patients despite the treatment with tumor necrosis factor-alpha blockers: a two-year prospective observational study. Joint Bone Spine 2014; 81: 421-5.

20. Amital H, Barak V, Winkler RE, Rubinow A. Impact of treatment with infliximab on serum cytokine profile of patients with rheumatoid and psoriatic arthritis. Ann N Y Acad Sci 2007; 1110: 649-60.

21. Jensen P, Wiell C, Milting K, et al. Plasma YKL-40: a potential biomarker for psoriatic arthritis? J Eur Acad Dermatol Venereol 2013; 27: 815-9.

22. Pittoni V, Bombardieri M, Spinelli FR, et al. Anti-tumour necrosis factor (TNF) alpha treatment of rheumatoid arthritis (infliximab) selectively down regulates the production of interleukin (IL) 18 but not of IL12 and IL13. Ann Rheum Dis 2002; 61: 723-5.

23. Bresnihan B, Roux-Lombard P, Murphy E, et al. Serum interleukin 18 and interleukin 18 binding protein in rheumatoid arthritis. Ann Rheum Dis 2002; 61: 726-9.

24. van Kuijk AW, DeGroot J, Koeman RC, et al. Soluble biomarkers of cartilage and bone metabolism in early proof of concept trials in psoriatic arthritis: effects of adalimumab versus placebo. PLoS One 2010; 5: e12556.

25. Chandran V, Shen H, Pollock RA, et al. Soluble biomarkers associated with response to treatment with tumor necrosis factor inhibitors in psoriatic arthritis. J. Rheumatol 2013; 40: 866-71.

26. Mahendran SM, Chandran V. Exploring the psoriatic arthritis proteome in search of novel biomarkers. Proteomes 2018; 6: 5 .

27. Eder L, Chandran V, Gladman DD. Repair of radiographic joint damage following treatment with etanercept in psoriatic arthritis is demonstrable by 3 radiographic methods. J Rheumatol 2011; 38: 1066-70.

28. Cauza E, Hanusch-Enserer U, Frischmuth K, et al. Short-term infliximab therapy improves symptoms of psoriatic arthritis and decreases concentrations of cartilage oligomeric matrix protein. J Clin Pharm Ther 2006; 31: 149-152. 